\title{
DISTROFIA MIOTÔNICA
}

\section{ESTUDO DA CORRELACCÃO CLÍNICO-GENÉTICA EM UM PAR FAMILIAR (PAI-FILHO)}

\author{
UMBERTINA C. REED*, MARIA RITA PASSOS-BUENO**, SUELY K. NAGAHASHI-MARIE ${ }^{* * *,}$ \\ ANTONIA CERQUEIRA**, LUCIA I.Z MENDONÇA*, JOSÉ ANTONIO LEW****, \\ ARON DIAMENT ${ }^{\star \star \star \star}$, MAYANA ZATZ $Z^{\star \star \star \star *}$
}

\begin{abstract}
RESUMO - É relatado o caso de um paciente com início da sintomatologia aos 7 anos de idade, cujo estudo genético e o de seu pai, portador assintomático, revelou um fragmento adicional de DNA, maior no paciente sintomático do que no pai portador. Os dados provenientes do estudo genético deste par familiar em geraçð̃es sucessivas, provavelmente o primeiro realizado no Brasil desde a recente descoberta por autores americanos do tipo de anormalidade genética presente na distrofia miotônica, vêm salientar a explicação genética para o fenômeno clínico da antecipação. São comentados resumidamente os principais avanços no campo da genética molecular desta doença e sua correlação ao início precoce da sintomatologia, como ocorreu no nosso paciente.
\end{abstract}

PALAVRAS-CHAVE: distrofia miotônica, doença de Steinert, genética molecular, expansão do DNA, fenômeno da antecipação.

Myotonic dystrophy: analysis of clinical-genetic correlation in a parent-child pair

SUMMARY - We report the case of a child with myotonic dystrophy (DM) with symptoms begining at the age of seven, whose genetic study showed an additional DNA fragment, greater than of his father, an asymptomatic carrier. The clinical and molecular analysis of this parent-child pair are probably the first described in Brazil, since the recent discovery of genetic abnormality in DM by American and European researchers, that explained the long-debated phenomenon of "anticipation" in this disease. The main advances in molecular genetics in DM and its correlation with increasing severity and earlier onset of the symptoms in sucessive generations of a family are commented briefly.

KEY WORDS: myotonic dystrophy, Steinert disease, molecular genetics, expanding DNA sequence, anticipation phenomenon.

A distrofia miotônica (DM) ou doença de Steinert é a forma de distrofia muscular mais frequentemente referida, com incidência de 1:8000 ${ }^{16}$. Embora a média da idade de início da sintomatologia se situe entre 20 e 25 anos, existe também uma forma congênita com grave comprometimento neuromuscular ao nascimento e uma forma com comprometimento muscular mínimo, mais encontrada em idades avançadas, caracterizada sobretudo por catarata ${ }^{8} . \mathrm{Na}$

Estudo da Clínica Neurológica (CN) da Faculdade de Medicina (FM) da Universidade de São Paulo (USP) e do Departamento de Biologia (DB) do Instituto de Biociências (IB) da USP: *Professor Assistente Doutor, CN/FMUSP; **Bióloga, DB/IBUSP; ***Médica, CN/FMUSP; ****Professor Associado, CN/FMUSP; *****Professor Associado, DB/IBUSP. Aceite: 12-abril-1994.

Dra. Umbertina C. Reed - Divisão de Clínica Neurológica, Hospital das Clínicas, FMUSP - Av. Dr. Enéas de Carvalho Aguiar, 255 - 05403-900 São Paulo SP - Brasil. 


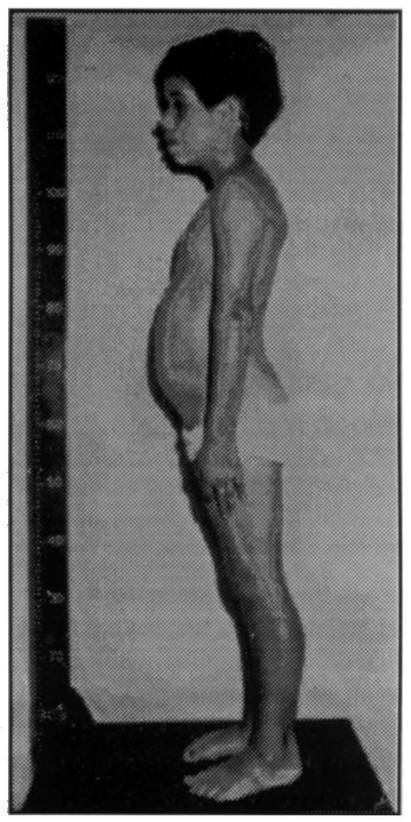

Fig 1. Paciente aos 9 anos de idade: notar a paresia facial, a semiptose palpebral e o fenótipo de distrofia miotônica.

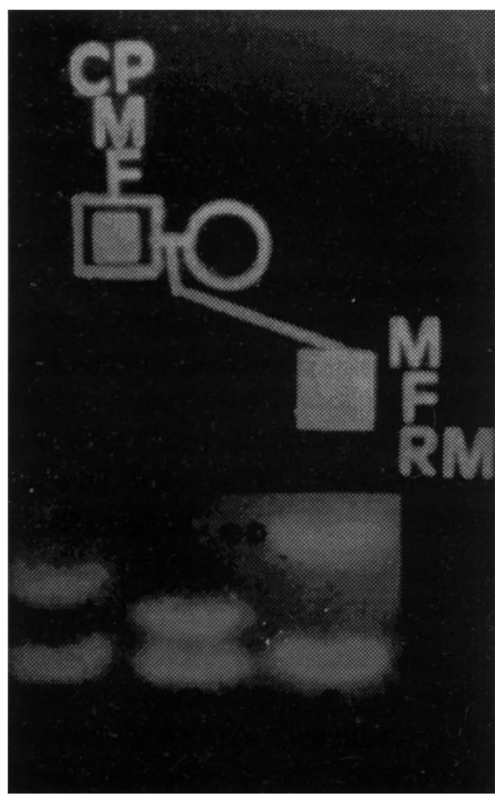

Fig 3. Análise do DNA por "Southern blot": A. pai portador com banda menor $\left({ }^{*}\right)$; $B$. mãe normal; $C$. paciente sintomático com banda maior (**).

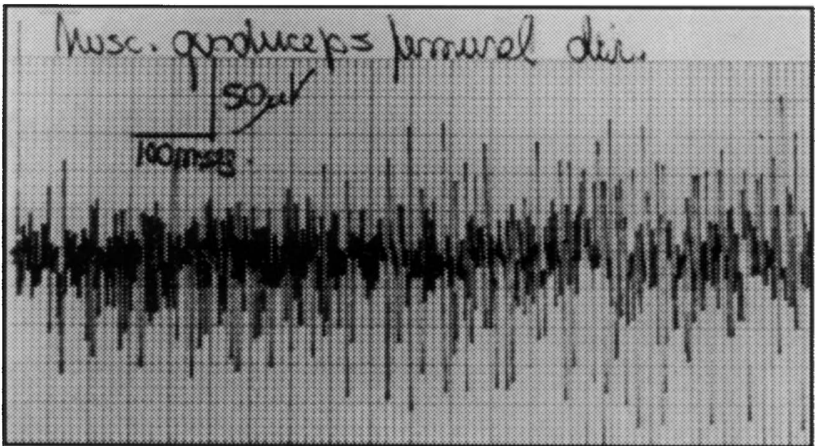

Fig 2. Eletromiografia do músculo quadriceps femoral direito: notar as intensas descargas miotônicas de amplitudes variáveis.

forma clássica do adulto, o início da sintomatologia na primeira década é raro ${ }^{2,8,11,12}$, sendo descrito sobretudo nas publicações que avaliam pares familiares, para ilustrar o fenômeno da antecipação $0^{9,10}$.

Apesar do tipo de herança com expressividade variável ser reconhecido de longa data, somente a partir de 1985 os estudos de genética molecular identificaram o gene anômalo situado no cromossoma $19 \mathrm{q}^{8}$, não tendo sido possível, ainda, a detecção de uma proteína anormal. Recentemente, em 1992, autores europeus e americanos ${ }^{1,3.5 .6}$, descreveram que nos doentes com DM ocorre uma sequência instável anormal de DNA, isto é, a expansão de um trinucleotídeo CTG, cujo tamanho está aparentemente correlacionado à idade de início e à severidade da sintomatologia. $O$ interesse na apresentação deste caso resulta da observação de uma grande expansão de DNA no probando, enquanto seu pai, que é o transmissor do gene, tem um fragmento muito pouco aumentado e é totalmente assintomático aos $\mathbf{3 7}$ anos de idade.

\section{RELATO DO CASO}

TOL, paciente branco, do sexo masculino, com 10 anos de idade. Começou a sintomatologia aos 7 anos de idade, quando foram notadas quedas frequente e dificuldade progressiva para correr e deambular. $O$ déficit motor coincidiu com o início da vida escolar, sendo também relatada dificuldade de aprendizagem. Antecedentes gestacionais, individuais e desenvolvimento neuropsicomotor sem anormalidade digna de nota. Quanto aos antecedentes familiares, embora não se tenha encontrado qualquer anormalidade digna de nota, é relevante ressaltar que o pai do probando é assintomático, não apresentando calvície, catarata, sintomatologia de doença cardíaca ou fenômeno miotônico, mesmo ao estudo eletromiográfico. $O$ probando tem 2 irmãos gêmeos bivitelinos, ambos normais, e 4 tios paternos, todos normais, exceto um que apresenta deficiência mental desde a infância, aparentemente relacionada a traumatismo craniano mal caracterizado. Exame físico: 
acentuação da lordose lombar. Exame neurológico: deficiência mental leve, faixa educável; déficit motor distal em membros inferiores, grau IV nos segmentos proximais e grau II no grupo tibial anterior; reflexos profundos conservados; semiptose palpebral bilateral; paresia facial bilateral (Fig 1). Tomografia computadorizada e ressonância nuclear magnética do crânio normais. Avaliação cardiológica (ECG, EcoCG, RX de tórax) compatível a estenose pulmonar valvar e CIA sem repercussão clínica. Avaliação endocrinológica (glicemia, GTT, testosterona) normal. Imunoglobulinas séricas normais. Enzimas musculares: CPK 221 U/L, DHL 313 U/L. Biópsia muscular: achados inespecíficos, compatíveis com o padrão muscular distrófico. Eletromiografia (Fig 2): no repouso, descargas miotônicas difusas em músculos proximais e distais dos 4 membros, de predomínio nos membros inferiores. $\mathrm{Na}$ contração leve, padrão de interferência do tipo paradoxal, indicando acometimento do tipo miopático, principalmente nos membros inferiores. Estudo genético: a análise do material genético (DNA) por técnica de "Southern blot" no paciente e nos seus pais, com o uso da enzima EcoRI, revelou: duas bandas normais na mãe (de $9 \mathrm{~kb}$ ); uma banda de $9 \mathrm{~kb}$ e outra de $10 \mathrm{~kb}$ no pai; e uma de 9 e outra de $13,4 \mathrm{~kb}$ no probando afetado (Fig 3). O mesmo exame foi realizado também nos dois irmãos gêmeos do probando, bem como no tio paterno que apresentava deficiência mental, fornecendo resultado normal.

\section{COMENTÁRIOS}

Nosso paciente, com início da sintomatologia aos 7 anos de idade, enquadra-se na forma de DM de início na infância, que constitui grupo relativamente pequeno ${ }^{2,7,8,11,12}$. O fenômeno da antecipação, já conhecido há 70 anos $^{6,16}$, consiste de início mais precoce e maior gravidade em gerações sucessivas e baseia-se nos estudos que avaliam pares familiares (pais e filhos) ${ }^{9,10}$. Os relatos de casos de início muito precoce, na primeira infância, com aspectos clínicos semelhantes à forma congênita, porém menos severos (nos quais não é possível comprovar o início ao nascimento) ${ }^{6}$, geralmente são transmitidos pela mãe.

$O$ interesse no enfoque de nosso paciente consiste no fato de: (a) o gene ter transmissão paterna; (b) ter ocorrido uma expansão muito grande no filho em comparação a seu pai, que tem um fragmento minimamente aumentado. As primeiras publicações acerca deste tipo de anormalidade do DNA são recentes, tendo sido efetuadas por diferentes autores em $1992^{1,3,5,6}$. Fundamentalmente, na DM existe um fragmento alterado de DNA ${ }^{1,5,6}$, que se caracteriza por uma expansão, ou seja, um aumento de comprimento, provocado por um excesso de repetições da sequência citosina-timinaguanidina (C-T-G). Nos indivíduos normais a sequência se repete até 27 vezes, ao passo que, nos indivíduos afetados o número de repetições pode chegar a 2000 ou mais ${ }^{6}$. A expansão da sequência anormal é identificável por "Southern blot" a partir de aumentos da banda de DNA de 0,5 kb (500 pares de bases). No caso de aumentos pequenos, são utilizadas outras técnicas (hibridização com enzima PStI ou técnica de reação em cadeia da polimerase ou PCR). $O$ tamanho do fragmento está relacionado à idade de início da sintomatologia e ao grau de gravidade clínica. Assim, pacientes com a forma congênita severa exibem fragmentos de DNA maiores, ao passo que indivíduos adultos com comprometimento discreto possuem bandas pouco maiores do que indivíduos normais. Em gerações sucessivas vai se processando expansão progressiva da repetição da sequência das bases, que explica a maior gravidade do quadro clínico e o início mais precoce da sintomatologia (fenômeno da antecipação), como ocorreu em nosso paciente.

Ainda não se conhece com exatidão o mecanismo pelo qual a anormalidade do DNA produz o comprometimento muscular e sistêmico na DM. Acredita-se que a sequência alterada de aminoácidos origine uma proteinoquinase defeituosa (que, quando normal, modula a função dos canais de íons do músculo esquelético) que interfere no mecanismo de fosforilação ao nível dos canais de íons ${ }^{14}$.

Não é possível relacionar as características clínicas ou genéticas da DM às propriedades da proteinoquinase envolvida, prevista pela sequência. A repetição instável está localizada em 3'-UTR do gene, o que possibilita a correlação quantitativa dos efeitos da expansão a alterações na regulação da transcrição ou translação ou na estabilidade do RNA mensageiro, ou mesmo no funcionamento dos genes vizinhos. O reconhecimento da sequência de repetição instável e seu modo de transmissão nas famílias tem auxiliado na elucidação dos vários problemas clínicos e genéticos da $\mathrm{DM}^{7}$. 
Esses avanços no campo da genética molecular se revestem de particular importância clínica porque, além de permitirem o reconhecimento e, portanto, o aconselhamento genético de uma série de indivíduos assintomáticos, ou apenas minimamente afetados ${ }^{4,6,15}$, propiciam maior eficácia aos métodos de diagnóstico pré-natal ${ }^{6,13}$.

\section{REFERÊNCIAS}

1. Aslanidis C, Jonsen G, Armeniya C. Cloning of the essential myotonic dystrophy region and mapping of the putative defect. Nature 1992, 355: 548-551.

2. Bethlem J, Knobbout CE. Neuromuscular diseases. Oxford: Oxford Univ Press, 1987, p 107-119.

3. Brook JD, Mc Currach ME, Harley HJ. Molecular basis of myotonic dystrophy. Cell 1992, 68: 799-808.

4. Brunner HG, Nillesen W, van Oost BA, Jansen J, Wieringa B, Ropers H, Smeets HJM. Presymptomatic diagnosis of myotonic dystrophy. J Med Genet 1992, 29: 780-784.

5. Buxton J, Shelbourne P, Davies J. Detection of an unstable fragment of DNA specific to individuals with myotonic dystrophy. Nature 1992, 355: 547-548.

6. Harley HG, Rundle SA, Reardon W, Myring J, Crow S, Brook JD, Harper PS, Duncan JS. Unstable sequence in myotonic dystrophy. Lancet 1992, 339: 1125-1128.

7. Harley HG, Rundle SA, MacMillan JC, Myring J, Brook D, Crow S, Reardon W, Fenton I, Shaw DJ, Harper PS. Size of the unstable CTG repeat sequence in relation to phenotype and parental transmission in myotonic dystrophy. Am J Hum Genet 1993, 52: 1164-1174.

8. Harper PS. Myotonic dystrophy. Philadelphia: Saunders, 1989.

9. Howeler CJ, Bush HFM, Geroedets JPM, Niermeiyer MF, Staal A. Anticipation in myotonic dystrophy: fact or fiction? Brain 1989, 112: 779-797.

10. Hunter A, Tsilfidis C, Meltler G, Jacob P, Mahadevan M, Surth L, Korneluk R. The correlation of age of onset with CTG trinucleotide repeat amplification in myotonic dystrophy. J Med Genet 1992, 29: 774-779.

11. Jozefowicz RF, Griggs RC. Myotonic dystrophy. Neurol Clin 1988, 6: 455-472.

12. Morgenlander JC, Massey JM. Myotonic dystrophy. Semin Neurol 1991, 11: 236-243.

13. Myring J, Meredith AL, Harley HJ, Kohn G, Norbury G, Harper PS, Shaw DJ. Specific molecular prenatal diagnosis for the CTG mutation in myotonic dystrophy. J Med Genet 1992, 29: 785-788.

14. Ptacek LJ, Johnson KJ, Griggs RC. Genetics and physiology of the myotonic muscle disorders. N Engl J Med 1993, 328: 482-489.

15. Reardon W, Harley HG, Brook JD, Rundle SA, Crow S, Harper PS, Show DJ. Minimal expression of myotonic dystrophy: a clinical and molecular analysis. J Med Genet 1992, 29: 770-773.

16. Suthers GK, Huson SM, Davies KE. Instability versus predictability: the molecular diagnosis of myotonic dystrophy. J Med Genet 1992, 29: 761-765. 